\title{
Cognitive Correlates of Obsessive and Compulsive Symptoms in Huntington's Disease
}

\author{
Karen E. Anderson, M.D. \\ Elan D. Louis, M.D., M.S. \\ Yaakov Stern, Ph.D. \\ Karen S. Marder, M.D., M.P.H.
}

Objective: The authors' goal was to examine the frequency and type of obsessive and compulsive symptoms in Huntington's disease.

Method: The Yale-Brown Obsessive Compulsive Scale was used to assess obsessive and compulsive symptoms in 27 patients with Huntington's disease. The neuropsychological test performance of the 14 patients with at least one obsessive symptom and the seven patients with at least one compulsive symptom was compared with the performance of the patients without such symptoms.

Results: More than half of the patients with Huntington's disease endorsed obsessive or compulsive symptoms on the YaleBrown scale. Patients with obsessive or compulsive symptoms showed significantly greater impairment on neuropsychological tests measuring executive function than those without such symptoms.

Conclusions: Basal ganglia pathology in Huntington's disease may contribute to production of obsessive and compulsive symptoms and to executive performance deficits in these patients.
$\mathrm{P}$ features of Huntington's disease. Among 960 patients with Huntington's disease, Marder et al. (1) found that $22.3 \%$ had obsessive and compulsive symptoms at their first clinic visit, suggesting that these symptoms may be more common than previously recognized in this population. In the general population, Degonda et al. (2) found a weighted lifetime prevalence of obsessive and compulsive symptoms, without diagnosis of obsessive-compulsive disorder (OCD), of $5.5 \%$ by age 30 years. Obsessive and compulsive symptoms are also seen in other illnesses affecting the basal ganglia, including Fahr's disease, Sydenham's chorea, and Tourette's syndrome (3). However, Huntington's disease may provide a better model for the study of obsessive and compulsive symptoms because it can be diagnosed reliably and genetic testing is available.

The purpose of this study was to assess the frequency of obsessive and compulsive symptoms in patients with Huntington's disease and to assess the relationship between obsessive and compulsive symptoms and cognitive or motor dysfunction. Obsessive and compulsive symptoms were assessed by using the Yale-Brown Obsessive Compulsive Scale (4).

\section{Method}

All patients met clinical diagnostic criteria for Huntington's disease, based on clinical features of a movement disorder in the presence of a family history of Huntington's disease or a confirmatory genetic test. All of the patients participating in the study provided written informed consent in accordance with New York State Psychiatric Institute policy. Consecutive patients were assessed over a 10-month period as they came to the New York State Psychiatric Institute Huntington's Disease Center for routine visits. Patients deemed to be too impaired cognitively were not in- cluded. Twenty-seven patients were assessed with the Yale-Brown scale. The mean age of the Huntington's disease patients at the time of testing was 49.8 years (SD=9.8); 19 were men and eight were women.

As part of routine clinic care, the patients with Huntington's disease were evaluated with the Unified Huntington's Disease Rating Scale (5), which assesses four domains: neurological, psychiatric, neuropsychological, and functional. Neuropsychological measures included the Verbal Fluency (6), Symbol Digit Modalities (7), and Stroop Color and Word Test (8). The Total Functional Capacity Scale (9) was used to assess function and stage of illness. The Unified Huntington's Disease Rating Scale was administered to 22 patients within 1 month of their completing the Yale-Brown scale. The interval was within 2-6 months for the five other patients.

The Yale-Brown scale is a two-part measure of obsessive and compulsive symptoms. The first component is a checklist designed to elicit obsessive and compulsive symptoms. The second is a measure of symptom severity. Only the checklist section was administered for this study, and it was given by physicians. Patients were scored as having obsessive or compulsive symptoms if any category of current symptoms was endorsed at least once.

The patients with and without obsessive or compulsive symptoms were compared on stage of illness by using one-way analysis of variance (ANOVA). The two groups of patients were compared on the three stages of illness by using post hoc independent Student's $t$ tests. They were compared on duration of illness by using Student's independent t tests.

The patients with and without obsessive or compulsive symptoms were compared on neuropsychological test results by using one-way ANOVA, covaried for disease duration. Comparisons were made on functional impairment, stage and duration of illness, and motor disability.

\section{Results}

Twenty-seven Huntington's disease patients completed the Yale-Brown scale. Fourteen (52\%) endorsed at least one current obsessive symptom. The most frequently en- 
TABLE 1. Neuropsychological Assessment of 27 Patients With Huntington's Disease Who Did or Did Not Report Obsessions or Compulsions on the Yale-Brown Obsessive Compulsive Scale

\begin{tabular}{|c|c|c|c|c|c|c|c|c|c|c|}
\hline \multirow[b]{3}{*}{ Neuropsychological Measure } & \multicolumn{5}{|c|}{ Obsessions } & \multicolumn{5}{|c|}{ Compulsions } \\
\hline & \multicolumn{2}{|c|}{$\begin{array}{l}\text { Did Not Report } \\
\text { Obsessions } \\
(\mathrm{N}=13)\end{array}$} & \multicolumn{2}{|c|}{$\begin{array}{l}\text { Reported at Least } \\
\text { One Obsession } \\
(N=14)\end{array}$} & \multirow[b]{2}{*}{$p^{a}$} & \multicolumn{2}{|c|}{$\begin{array}{l}\text { Did Not Report } \\
\text { Compulsions } \\
(\mathrm{N}=20)\end{array}$} & \multicolumn{2}{|c|}{$\begin{array}{l}\text { Reported At Least } \\
\text { One Compulsion } \\
\qquad(\mathrm{N}=7)\end{array}$} & \multirow[b]{2}{*}{$\mathrm{p}^{\mathrm{a}}$} \\
\hline & Mean & SD & Mean & SD & & Mean & SD & Mean & SD & \\
\hline Verbal Fluency score $^{\mathrm{b}}$ & 25.15 & 11.42 & 17.62 & 7.30 & 0.11 & 22.63 & 10.97 & 18.00 & 7.07 & 0.20 \\
\hline Symbol Digit Modalities score & 29.50 & 7.60 & 20.85 & 9.16 & $0.04^{*}$ & 27.56 & 8.80 & 18.43 & 7.89 & $0.02^{*}$ \\
\hline \multicolumn{11}{|l|}{ Stroop Color and Word Test scores } \\
\hline Color naming & 46.67 & 11.97 & 39.82 & 15.22 & 0.24 & 44.19 & 14.72 & 41.57 & 12.12 & 0.43 \\
\hline Word reading $\mathrm{c}$ & 60.00 & 18.68 & 57.55 & 17.33 & 0.51 & 59.31 & 16.29 & 57.71 & 21.93 & 0.33 \\
\hline Interference ${ }^{\mathrm{C}}$ & 28.33 & 9.21 & 21.27 & 8.49 & 0.09 & 27.44 & 8.85 & 19.29 & 8.56 & 0.03 * \\
\hline
\end{tabular}

a One-way analysis of variance, covaried for duration of illness, used for all comparisons between groups (df=1, 24).

${ }^{\mathrm{b}}$ Data were missing for one patient in the group of patients who did not report obsessions.

c Number correct shown for all Stroop measures.

${ }^{*} \mathrm{p}<0.05$.

dorsed obsessions were aggressive obsessions, reported by seven patients $(26 \%)$, followed by contamination obsessions, endorsed by six (22\%). Seven patients (26\%) endorsed at least one current compulsive symptom. The most commonly reported compulsions were checking compulsions, reported by five patients (19\%). All seven patients with compulsive symptoms also reported obsessive symptoms. Two of these seven patients met DSM-IV criteria for current OCD.

Functional impairment and stage of illness, as measured by the Total Functional Capacity Scale, were not related to the number of current obsessive $(\mathrm{F}=1.95, \mathrm{df}=2,24$, $\mathrm{p}=0.17)$ or compulsive $(\mathrm{F}=0.37, \mathrm{df}=2,24, \mathrm{p}=0.70)$ symptoms. There was no significant difference in mean duration of illness in the patients with or without obsessive or compulsive symptoms $(\mathrm{F}=2.86, \mathrm{df}=1,25, \mathrm{p}=0.11)$. Chorea $(\mathrm{F}=0.41, \mathrm{df}=1,25, \mathrm{p}<0.53)$ and dystonia $(\mathrm{F}=0.11, \mathrm{df}=1,25$, $\mathrm{p}<0.75$ ) severity also did not differ significantly between the two groups.

The relationship between presence or absence of obsessive or compulsive symptoms on the Yale-Brown scale and performance on the Unified Huntington's Disease Rating Scale battery of neuropsychological tests was assessed by using one-way ANOVA, covaried for duration of illness. Although duration of illness did not differ significantly between groups, this correction was made because it was felt that duration of illness could affect neuropsychological test results. Patients with obsessive or compulsive symptoms tended to perform more poorly on all neuropsychological tests than those without obsessive or compulsive symptoms (Table 1). Patients with obsessive symptoms performed significantly worse on the Symbol Digit Modalities test than those without and showed lower scores on the interference section of the Stroop test. The patients who reported compulsive symptoms on the Yale-Brown scale scored significantly lower on the Symbol Digit Modalities and Stroop test interference measures than those without.

\section{Discussion}

Frontostriatal pathology has been implicated in primary OCD by numerous neuropsychological and imaging studies. The neuropsychological tests on which performance was significantly impaired in our patients with obsessive or compulsive symptoms assess executive capabilities. The Symbol Digit Modalities is an attentional task that also taps executive function, and the Stroop test is an executive task that involves response inhibition. The high rate of obsessive and compulsive symptoms in this study and their relationship to the impairment of executive function suggest that Huntington's disease patients, whose primary pathology is in the caudate, may be more prone to development of obsessive and compulsive symptoms.

Studies in OCD (10) have demonstrated similar neuropsychological deficits to those seen in these Huntington's disease patients on the Stroop test. Some functional imaging studies in OCD (11) have demonstrated caudate and frontal cortex abnormalities. Our patients with Huntington's disease identified aggressive and contamination obsessions as their two most common obsessions, seen in $26 \%$ and $22 \%$ of patients, respectively. Rasmussen and Eisen (12) found that contamination and pathological doubt were the most common obsessions in OCD patients. It is possible that the high rate of aggressive obsessions seen in these Huntington's disease patients may be related to the high frequency of aggressive behavior seen in this population, over $63 \%$ in a recent study (1). Movement disorders have been linked to aggressive obsessions in OCD, specifically in OCD patients with tics (13). On the basis of neuroimaging (14), specific subtypes of obsessive and compulsive symptoms have also been attributed to differences in neural circuitry.

All Huntington's disease patients are known to have frontostriatal pathology. However, those who develop obsessive and compulsive symptoms may have specific anterior and lateral orbitofrontal cortex and ventromedial caudate involvement, a pathway implicated in primary OCD (see reference 15 for a review). It is possible that the performance deficits and obsessive and compulsive symptoms 
reflect corticostriatal dysfunction. Study of obsessive and compulsive symptoms in Huntington's disease could lead to further insights into the neuropathology of OCD.

Received May 22, 2000; revision received Oct. 20, 2000; accepted Nov. 15, 2000. From New York State Psychiatric Institute, New York and the Department of Neurology and the Gertrude H. Sergievsky Center, Columbia University. Address reprint requests to Dr. Anderson, Sergievsky Center, P\&S Box 16, 630 West 168th St., New York, NY 10032; kea3@columbia.edu (e-mail).

Supported in part by the Huntington's Disease Society of America, New York, and the Hereditary Disease Foundation, Santa Monica, Calif.

\section{References}

1. Marder KS, Zhao H, Myers R, Cudkowicz M, Kayson E, Kieburtz K, Orme C, Paulsen J, Penney JB, Siemers E, Shoulson I (Huntington Study Group): Rate of functional decline in Huntington's disease. Neurology 2000; 54:452-458; correction, 54: 1712

2. Degonda M, Wyss M, Angst J: The Zurich Study, XVIII: obsessivecompulsive disorders and syndromes in the general population. Eur Arch Psychiatry Clin Neurosci 1993; 243:16-22

3. Salloway S, Cummings J: Subcortical disease and neuropsychiatric illness. J Neuropsychiatry Clin Neurosci 1994; 6:93-99

4. Goodman WK, Price LH, Rasmussen SA, Mazure C, Fleischmann RL, Hill CL, Heninger GR, Charney DS: The Yale-Brown Obsessive Compulsive Scale, I: development, use, and reliability. Arch Gen Psychiatry 1989; 46:1006-1011

5. Huntington Study Group: Unified Huntington's Disease Rating Scale: reliability and consistency. Mov Disord 1996; 11:136142
6. Benton AL, Hamsher KD: Multilingual Aphasia Examination Manual. Iowa City, University of lowa, 1978

7. Smith A: Symbol Digit Modalities Test Manual. Los Angeles, Western Psychological Services, 1973

8. Stroop JR: Studies of interference in serial verbal reactions. J Exp Psychol 1935; 18:643-662

9. Shoulson I, Kurlan RA, Rubin AJ, Goldblatt D, Behr J, Miller C, Kennedy J, Bamford KA, Caine ED, Kido DK, Plumb S, Odoroff C: Assessment of functional capacity in neurodegenerative movement disorders: Huntington's disease as a prototype, in Quantification of Neurologic Deficit. Edited by Munsat TL. Boston, Butterworth, 1989, pp 271-283

10. Hartston HJ, Swerdlow NR: Visuospatial priming and Stroop performance in patients with obsessive compulsive disorder. Neuropsychology 1999; 13:447-457

11. Saxena S, Brody L, Schwartz JM, Baxter LR: Neuroimaging and frontal-subcortical circuitry in obsessive-compulsive disorder. Br J Psychiatry Suppl 1998; 35:26-37

12. Rasmussen SA, Eisen JL: Clinical features and phenomenology of obsessive compulsive disorder. Psychiatr Annals 1989; 19: 67-73

13. Leckman JF, Grice DE, Barr LC, de Vries ALC, Martin C, Cohen DJ, McDougle CJ, Goodman WK, Rasmussen SA: Tic-related and non-tic-related obsessive compulsive disorder. Anxiety 1994/ 1995; 1:208-215

14. Rauch SL, Dougherty DD, Shin LM, Alpert NM, Manzo P, Leahy L, Fischman AJ, Jenicke MA, Baer L: Neural correlates of factoranalyzed OCD symptom dimensions: a PET study. CNS Spectrums 1998; 3(7):37-43

15. Rauch SL, Whalen PJ, Dougherty D, Jenike MA: Neurobiologic models of obsessive-compulsive disorder, in Obsessive-Compulsive Disorders: Practical Management, 3rd ed. Edited by Jenike MA, Baer L, Minichiello WE. St Louis, Mosby, 1998, pp 222-317 